\title{
HUBUNGAN ANTARA BEBAN SUBJEKTIF DENGAN KUALITAS HIDUP PENDAMPING (CAREGIVER) PASIEN SKIZOFRENIA
}

\author{
Anisa Fitriani dan Agustin Handayani \\ Fakultas Psikologi, Universitas Islam Sultan Agung, Jl. Raya Kaligawe Km. 4 Semarang \\ Email: anisa.fitriani@unissula.ac.id
}

\begin{abstract}
Abstrak
Skizofrenia merupakan salah satu gangguan jiwa yang bersifat kronis. Orang yang terkena gangguan skizofrenia atau yang sering disebut dengan Orang Dengan Skizofrenia (ODS) akan mengalami gangguan dalam berbagai aspek kehidupan. Kondisi tersebut membuat ODS membutuhkan bantuan dari orang lain untuk menjalankan fungsinya dalam kehidupan sehari-hari selama proses pemulihan. Menjadi pendamping, atau yang sering disebut dengan caregiver, bagi anggota keluarga yang mengalami skizofrenia bukanlah hal yang mudah dijalankan bagi semua orang. Peran tersebut seringkali menimbulkan berbagai macam beban yang dipersepsikan berbeda oleh masing-masing orang. Beban tersebut dapat berdampak secara menyeluruh pada seluruh aspek kehidupan yang berkaitan dengan kualitas hidup. Tujuan dari penelitian ini adalah untuk mengetahui hubungan antara beban subjektif dengan kualitas hidup caregiver skizofrenia. Desain penelitian yang digunakan adalah penelitian kuantitatif. Subjek terdiri dari 50 caregiver skizofrenia di desa X kota Yogyakarta. Data kualitas hidup caregiver diperoleh dengan skala World Health Organization of Quality of Life-Bref (WHOQOL-BREF) dan data beban subjektif caregiver diperoleh dengan Zarit Caregiver Burden Scale (ZCBS). Hasil penelitian ini menunjukkan bahwa terdapat korelasi negatif yang signifikan antara kualitas hidup dengan beban subjektif. Semakin tinggi kualitas hidup caregiver maka semakin rendah beban yang dirasakan. Semakin berat beban yang dirasakan oleh caregiver maka akan semakin rendah tingkat kualitas hidup.
\end{abstract}

Kata Kunci: Caregiver, skizofrenia, kualitas hidup, beban subjektif

\section{THE CORRELATION BETWEEN SUJECTIVE BURDEN AND QUALITY OF LIFE OF SCHIZOPHRENIA'S CAREGIVERS}

\begin{abstract}
Schizophrenia is a chronic mental disorder. Sometimes people with schizophrenia have difficulties in various aspects of life. They need help from others to carry out their functions in daily life during the recovery process. Being a caregiver for schizophrenic patient is not easy role for everyone. This role often creates various kinds of burden that are perceived differently by each person. This burden can have a comprehensive impact on all aspects of life related to quality of life. The purpose of this study was to know the relationship between subjective burden and quality of life of schizophrenic's caregivers. The research design used is quantitative research. The subject consisted of 50 schizophrenic caregivers in village $X$ in Yogyakarta city. The quality of life of caregivers was obtained by the scale of quality of life from World Health Organization (WHOQOL-BREF) and the caregiver's subjective burden data was obtained by Zarit Caregiver Burden Scale (ZCBS). The results of this study indicate a significant correlation between quality of life and subjective burden. The higher the quality of life of caregivers, the lower the burden received. The more weight of burden received by the caregiver, the lower the quality of life.
\end{abstract}

Key words: Caregiver, schizophrenia, quality of life, subjective burden 


\section{PENDAHULUAN}

Skizofrenia merupakan salah satu gangguan kejiwaan yang paling banyak terjadi di masyarakat. Skizofrenia termasuk dalam gangguan psikotik yang ditandai dengan munculnya gangguan dengan realita, gangguan proses pikir, emosi, persepsi, dan perilaku (Ibrahim, 2011). Skizofrenia berasal dari dari bahasa Yunani schistos yang artinya terpotong atau terpecah dan phren yang berarti otak. Penderita skizofrenia akan mengalami keretakan atau pemisah antara pikiran, perasaan, dan perilaku. Terdapat beberapa faktor resiko seseorang mengalami skziofrenia. Kaplan dkk (1997) mengemukakan etiologi skizofrenia meliputi faktor biologis, genetik, psikonegesis, proses pembelajaran, diatesis stres, faktor keluarga dan sosial.

Berdasarkan data yang diperoleh WHO (2015), sekitar 26 juta orang di dunia mengalami gangguan jiwa berat dengan perbandingan 1 dari 4 anggota keluarga mengalami gangguan jiwa. Skizofrenia juga merupakan salah satu gangguan psikotik. Psikotik sendiri digunakan untuk menggambarkan kondisi seseorang saat mengalami gangguan dengan kenyataan. Contohnya adalah mengalami halusinasi, yaitu mendengar suara-suara yang sebenarnya tidak ada sumbernya atau melihat sesuatu yang tidak nyata. Gangguan psikotik disebabkan karena adanya disfungsi dalam otak sehingga seseorang akan mengalami kesulitan untuk memisahkan antara hal-hal yang tidak nyata dengan kenyataan. Penderita gangguan psikotik juga dapat menunjukkan perilaku aneh tanpa sadar (Compton \& Broussard, 2009).

Prevalensi penderita gangguan jiwa menurut WHO sekitar 0,2\% sampai $2 \%$ atau 24 juta jiwa di seluruh dunia dengan perbandingan yang sama antara laki-laki dan perempuan. Menurut data yang diperoleh dari Riset Kesehatan Dasar pada tahun 2013, penderita gangguan jiwa berat, termasuk skizofrenia, di Indonesia sebesar 1,7 jiwa per mil. Jumlah terbanyak berada di DIY Yogyakarta, Aceh, Sulawesi Selatan, Bali, dan Jawa Tengah (Riskades, 2013).

Skizofrenia merupakan salah satu gangguan jiwa yang bersifat kronis. Penyakit kronis adalah penyakit yang perjalanannya berkepanjangan dan jarang sembuh secara sempurna. Dengan demikian pasien skizofrenia biasanya akan membutuhkan perawatan jangka panjang (Fitrikasari dkk, 2002; Badriyah, 2011). Penderita skizofrenia biasanya sulit dipulihkan dan jika bisa sembuh akan membutuhkan waktu yang lama dan cenderung tidak bisa pulih sepenuhnya seperti sebelum terkena skizofrenia. Kondisi tersebut yang akhirnya menjadi sebab dibutuhkannya bantuan dari orang lain bagi penderita skizofrenia. Bantuan dapat didapatkan dari keluarga dan orang-orang terdekat (Siswanto, 2007). Penderita pada umumnya juga mengalami gangguan untuk menjalankan fungsinya dalam kehidupan sehari-hari, baik dari segi fisik, psikologis, maupun sosial (Rubbyana, 2012). Penderita skizofrenia, yang selanjutnya disebut dengan ODS (Orang Dengan Skizofrenia), umunya mengalami permasalahan untuk menjalankan fungsinya dalam kehidupan sehari-hari. Mereka cenderung membutuhkan bantuan dari orang lain, terutama dari keluarga atau orang-orang terdekat (Sadock \& Sadock, 2007).

Menjalankan peran sebagai pendamping (caregiver) bagi anggota keluarga yang mengalami skizofrenia terkadang bukan sesuatu yang mudah. Kondisi ini seringkali menimbulkan berbagai dampak munculnya emosi negatif, seperti rasa frustasi, malu, marah, rasa bersalah dan beberapa perasaan tidak nyaman lainnya (Makmuroch, 2014). Salah satu hasil penelitian menunjukkan bahwa sebagian besar caregiver mengalami rasa tidak nyaman, 80 persen dari caregiver skizofrenia merasa terbebani dan 71 persen mengalami ketegangan komunikasi dengan anggota keluarga (Fitrikasari dkk, 2012).

14 P-ISSN 1907-8455 
Caregiver dapat didefinisikan sebagai seseorang yang memiliki tanggung jawab dalam proses perawatan pasien dan melakukan kontak personal dengan pasien minimal satu minggu sekali (Dorian $\mathrm{dkk}, 2008)$. Definisi lain tentang caregiver mengatakan bahwa caregiver adalah anggota keluarga yang tinggal dengan pasien, memiliki kedekatan dalam kehidupan sehari-hari, melakukan perawatan, dan berinteraksi selama dua tahun lebih (Swaroop dkk, 2013). Orang yang merawat dan bertanggungjawab pada pasien diatur dalam Undang-Undang Kesehatan Jiwa No. 18 tahun 2014, yaitu suami/istri, orang tua, anak, saudara kandung (minimal 17 tahun). Caregiver dalam hal ini merupakan keluarga, wali, pengampu atau pejabat yang memiliki wewenang sesuai dengan peraturan perundang-undangan.

Caregiver dibedakan menjadi formal caregiver dan informal caregiver. Formal caregiver adalah bagian dari sistem pelayanan, seperti Rumah Sakit, dan mendapatkan bayaran maupun sukarela. Informal caregiver adalah seseroang yang merupakan anggota keluarga, tetangga, atau teman yang memberikan perawatan pada pasien tanpa mendapatkan bayaran, paruh waktu atau sepanjang waktu, dan tinggal bersama ataupun terpisah dengan pasien (Greenberg dkk, 2006). Peneliti memfokuskan pada informal caregiver dalam penelitian ini, yang merupakan anggota keluarga dari penderita skizofrenia. Hal ini dilandasi oleh hasil survey yang menunjukkan bahwa sebagian besar penderita skizofrenia mendapatkan perawatan di rumah. Hanya 3,5\% yang mendapatkan pelayanan di Rumah Sakit Jiwa, Rumah Sakit Umum, atau Pusat Kesehatan Masyarakat dengan fasilitas yang memadai (Gani, 2014). Hasil penelitian yang dilakukan oleh Dewi dkk (2013) juga menunjukkan bahwa 40-90\% caregiver bagi pasien skizofrenia adalah informal caregiver dan $77 \%$ diantaranya merupakan anggota keluarga pasien.

Menjadi caregiver bagi pasien yang mengalami penyakit kronis dapat berpengaruh pada tingkat kualitas hidup (Yenny \& Herwana, 2006). Menjadi caregiver dapat menimbulkan ketegangan, tekanan, dan memicu rasa terbebani. Kondisi tersebut yang kemudian berdampak pada penurunan kualitas hidup (Stanley \& Shwetha, 2006; Panigrahi dkk, 2014). Penelitian yang dilakukan di Chili dan Prancis oleh Boyer, dkk (2012) menunjukkan bahwa level kualitas hidup caregiver skizofrenia cenderung rendah. Hal tersebut didukung oleh hasil penelitian yang dilakukan oleh Margetic dkk (2013) yang menunjukkan bahwa caregiver skizofrenia memiliki skor kualitas hidup yang lebih rendah dibandingkan dengan skor kualitas hidup caregiver untuk pasien gangguan jiwa lainnya. Masih adanya stigma tentang gangguan jiwa dalam masyarakat juga dapat menimbulkan efek psikologis serta berbagai permasalahan psikososial yang berdampak pada penurunan kualitas hidup (Lylayuvery, 2008).

Kualitas hidup menurut World Health Organization (WHO) adalah konstruk multidimensional yang mencakup kesehatan fisik, mental, kesejahteraan sosial yang utuh dan bukan hanya ketiadaan penyakit dan kelemahan (Peterson, 2011). Kualitas hidup dapat dideskripsikan untuk mengukur kondisi emosional, fisik, sosial, dan kemampuan dalam melakukan fungsi dalam keseharian. Menurut WHO (1996), kualitas hidup mencakup beberapa aspek, yaitu fisik, psikologis, hubungan sosial, dan kondisi lingkungan. Menurunnya kualitas hidup caregiver skizofrenia dapat terjadi karena beberapa faktor dari aspek fisik, psikologis, sosial dan lingkungan. Bertambahnya energi yang harus dikeluarkan berdampak pada berkurangnya waktu istirahat. Kondisi ini dapat menimbulkan rasa lelah secara fisik dan psikologis, munculnya permasalahan dalam hubungan sosial karena rasa malu, serta bertambahnya beban keuangan.

Keempat faktor tersebut menjadi acuan untuk menyusun skala yang digunakan dalam penelitian ini. Faktor pertama adalah kesehatan fisik dan kemampuan fungsional. Hal tersebut merupakan faktor yang berasal dari kondisi internal kesehatan tubuh individu secara biologis yang terlihat dari seberapa 
baik fungsi dari bagian-bagian tubuh, sistem-sistem dalam tubuh, maupun fungsi biologis tubuh secara keseluruhan. Kesehatan fisik seseorang dalam menjalankan fungsi dan peran dalam kehidupan seharihari sehingga dapat meningkatkan kualitas hidup.

Faktor kedua adalah kesehatan psikologis. Kesejahteraan diri, serta kepuasan hidup merupakan faktor psikis yang bersifat subjektif, serta menggambarkan persepsi pikiran terhadap kehidupan yang telah dijalani. Selain itu juga terdapat keyakinan-keyakinan psikologis, perasaan-perasaan positif, kemampuan kognitif, dan afektif. Kesehatan psikis akan mempengaruhi dan membawa individu pada pemikiran-pemikiran positif yang pada akhirnya akan berdampak pada penilaian bahwa dirinya memiliki kualitas hidup yang baik. Faktor ketiga yaitu hubungan sosial, aktivitas, dan partisipasi yang merupakan faktor eksternal yang datang dari internal individu dengan lingkungan sekitar. Meliputi kualitas interaksi, kualitas hubungan yang dapat membantu individu untuk mengembangkan peranperan dalam masyarakat dan meningkatkan kualitas hidup individu tersebut. Individu yang memiliki kualitas dan kuantitas dalam berinteraksi dengan orang lain, baik dengan orang-orang di sekitarnya ataupun orang-orang lain, akan memiliki kepuasan hidup yang lebih baik jika dibandingkan dengan yang tidak.

Faktor terakhir adalah keadaan lingkungan hidup dan kondisi sosio-ekonomi. Hal ini merupakan faktor eksternal yang datang dari keadaan lingkungan sekitar secara umum, status sosio-demografik, kondisi alam, kondisi ekonomi serta budaya yang ada dalam lingkungan. Beberapa hal tersebut akan memberikan pengaruh pada kualitas hidup seseorang. Keadaan lingkungan yang kondusif akan membantu individu dalam menciptakan persepsi atas kehidupan yang baik dan kemudian akan berpengaruh pada kualitas hidup.

Selain dapat memberikan dampak pada kualitas hidup, menjadi caregiver dapat menimbulkan perasaan terbebani. Menjalankan peran sebagai caregiver membutuhkan pengetahuan, kemauan dan kesabaran. Kondisi tersebut dapat menjadi pemicu munculnya tekanan dan beban karena untuk merawat penderita gangguan skizofrenia bukanlah hal yang ringan. Beban yang dirasakan antara caregiver satu dengan lainnya pun berbeda (Nainggolan \& Hidajat, 2013).

Adanya beban selama proses perawatan akan dirasakan oleh sebagian besar caregiver. Hal ini dapat dilihat dari hasil penelitian yang telah dilakukan oleh Fitrikasari dkk (2012) yang menunjukkan bahwa 89 dari 100 caregiver bagi penderita skizofrenia di Rumah Sakit Jiwa Daerah Dr. Amino Gondohutomo Semarang merasa terbebani dengan kondisi penderita skizofrenia. Aspek yang paling besar adalah berkurangnya rasa nyaman. Penelitian yang dilakukan oleh Darwin (2013) di Rumah Sakit Jiwa Islam Klender Jakarta juga menunjukkan kondisi yang hampir sama, 67,8\% dari 118 caregiver skizofrenia merasa terbebani selama proses perawatan pada anggota keluarga yang menderita skizofrenia.

Beban yang dirasakan oleh caregiver dapat menjadi sumber stres. Beban tersebut dapat dibagi menjadi beban objektif dan subjektif. Beban objektif adalah beban yang terkait dengan berbagai permasalahan praktis selama proses perawatan, seperti terganggunya kegiatan di lingkungan sosial, berkurangnya waktu luang dan waktu istirahat serta bertambahnya pengeluaran keuangan. Beban subjektif adalah beban yang terkait dengan reaksi emosional, seperti munculnya rasa cemas, takut, sedih, marah, rasa bersalah, dan berbagai tekanan lainnya. Dampak dari beban yang dirasakan oleh caregiver dapat berpengaruh pada kondisi fisik maupun psikis.

Beban yang dirasakan oleh caregiver satu dengan lainnya dapat berbeda-beda karena dipengaruhi oleh persepsi masing-masing. Persepsi positif yang dimiliki oleh caregiver terhadap beban selama 
menjadi caregiver turut berpengaruh pada tekanan dalam situasi sulit tersebut (Prasastyagoya, dkk, 2013). Hal tersebut menunjukkan bahwa terdapat persepsi yang berbeda-beda pada masing-masing caregiver terhadap beban yang dirasakan atau yang sering disebut dengan beban subjektif. Persepsi yang berbeda-beda tersebut akan memberikan dampak yang berbeda pula.

Goodhead \& McDonald (2007) menyatakan bahwa peran sebagai caregiver dapat memberikan dampak positif. Pengaruh positif tersebut antara lain adalah adanya peningkatan hubungan dengan pasien, meningkatnya rasa tanggung jawab, dan adanya saling berbagi cinta dan dukungan. Selain itu juga dapat meningkatkan pengembangan pribadi, perasaan lebih dekat dengan pasien, dan meningkatkan harga diri (Savage \& Bailey 2004). Seseorang yang dapat mengatasi peristiwa yang penuh tekanan tanpa mengalami distress subjektif maka tekanan tersebut tidak akan menjadikan sebuah kondisi krisis (Brown dkk, 2003).

Persepsi merupakan fungsi psikis yang mempengaruhi pemahaman pada berbagai peristiwa dan kenyataan yang dihadapi oeh manusia. Islam memandang persepsi sebagai sebuah proses kognitif individu dalam memahami informasi. Proses pemahaman tersebut melibatkan panca indra, seperti mata, telinga, hidung, dan hati untuk merasakan. Pemahaman tersebut juga melibatkan hati dan akal. Fungsi indera manusia berfungsi sesuai dengan perkembangan fisik. Seseorang akan dapat merasakan berbagai pengaruh eksternal yang melibatkan perasaan-perasaan dan mempengaruhi persepsi dan pengetahuan (Najati, 2001).

Hal tersebut sesuai dengan apa yang telah dijelaskan oleh Islam dalam Al-Quran surat Yunus ayat 44 yang artinya: "Sesungguhnya Allah tidak berbuat zalim kepada manusia sedikitpun, akan tetapi manusia itulah yang berbuat zalim kepada diri mereka sendiri". Allah menciptakan manusia dengan alat indera agar manusia dapat merasakan apa yang sedang terjadi, pengaruh pada diri yang akhirnya menimbulkan perasaan-perasaan yang berbeda antara individu satu dengan lainnya.

Hal tersebut juga telah dijelaskan dalam Al-Quran Surat An-Nahl ayat 78 yang artinya: "Dan Allah mengeluarkan kamu dari perut ibumu dalam keadaan tidak mengetahui sesuatupun, dan Dia memberi kamu pendengaran, penglihatan dan hati, agar kamu bersyukur." Lalu dijelaskan lagi dalam Surat AsSajadah ayat 9 yang artinya: "Kemudian Dia menyempurnakan dan meniupkan ke dalamnya roh (ciptaan)-Nya dan Dia menjadikan bagi kamu pendengaran, penglihatan dan hati, (tetapi) kamu sedikit sekali bersyukur."

Berdasarkan penjelasan di atas maka dapat disimpulkan bahwa menjalankan peran sebagai caregiver dapat memberikan dampak negatif maupun positif. Hal tersebut dipengaruhi oleh persepsi beban yang dirasakan oleh masing-masing caregiver. Kapasitas beban yang dirasakan juga dapat berdampak pada beberapa aspek dalam kehidupan sehari-hari yang mengarah pada kualitas hidup. Penelitian ini bertujuan untuk mengetahui hubungan antara beban subjektif dengan kualitas hidup caregiver.

\section{METODE}

Penelitian ini dilaksanakan di daerah X kota Yogyakarta melalui kerjasama dengan Pusat Kesehatan Masyarakat (Puskesmas) setempat. Pemilihan lokasi penelitian didasarkan pada data yang menunjukkan bahwa lokasi tersebut merupakan salah satu daerah dengan angka pasien skizofrenia terbanyak di Jawa Tengah. Meningkatknya pasien skizofrenia juga akan diikuti oleh peningkatan caregiver. 
Teknik pengambilan sampel yang digunakan dalam penelitian ini adalah purposive sampling, yaitu dengan memilih subjek yang keterwakilannya sudah ditentukan berdasarkan beberapa kriteria penelitian. Subjek dalam penelitian ini sebanyak 50 orang caregiver skizofrenia yang memenuhi kriteria yang telah ditetapkan, yaitu laki-laki atau perempuan, berusia di atas 18 tahun, merupakan caregiver bagi anggota keluarga yang mengalami skizofrenia (informal caregiver), dan tinggal dalam satu rumah dengan anggota keluarga yang mengalami skizofrenia.

Data tingkat kualitas hidup caregiver diperoleh dengan skala kualitas World Health Organization of Quality of Life-Bref (WHOQOL-BREF). WHOQOL-BREF merupakan skala kualitas hidup yang dikembangkan oleh WHO (World Health Organization). Skala ini terdiri dari 26 item dan telah diadaptasi ke berbagai bahasa, termasuk diadaptasi ke dalam bahasa Indonesia dan sering digunakan untuk mengukur tingkat kualitas hidup. Semakin tinggi skor yang diperoleh dalam skala WHOQOL-BREF maka semakin tinggi tingkat kualitas hidup subjek. Berikut ini adalah penjelasan masing-masing dimensi dalam WHOQOL-BREF (1996):

1) Kesehatan fisik

Kesehatan fisik mencakup aspek kemampuan seseorang dalam menjalankan aktifitas sehari-hari, ketergantungan dengan obat, energi dan kelelahan, tidur dan istirahat, mobilitas, kapasitas atau kemampuan kerja, sakit dan ketidaknyamanan.

2) Psikologis

Dimensi ini terdiri dari self-image, perasaan negatif, perasaan positif, spiritualitas, kognitif (berfikir, ingatan, belajar, konsentrasi), dan harga diri.

3) Hubungan sosial

Hubungan sosial yang dimaksud adalah hubungan yang terkait interpersonal, dukungan sosial, dan aktivitas-aktivitas sosial yang ada di lingkungan sekitar.

4) Lingkungan

Dimensi lingkungan mencakup keuangan, kebebasan dan kenyamanan fisik, kesehatan dan kepedulian sosial dari orang lain terhadap dirinya, lingkungan rumah, kesempatan untuk mendapatkan informasi dan keahlian, serta lingkungan fisik seperti kebisingan, adanya polusi, keadaan lalu lintas, dan iklim.

Skala yang digunakan untuk mengukur persepsi subjektif beban caregiver adalah skala Zarit Caregiver Burden Scale (ZCBS). Skala ZCBS dikembangkan oleh Stephen Zarit yang awalnya digunakan untuk mengukur beban subjektif bagi pendamping pasien demensia. Namun, dalam perkembangannya skala ini digunakan untuk mengukur beban subjektif bagi pendamping pasien skizofrenia. ZCBS terdiri dari 22 aitem dan masing-masing memiliki rentang skala 0-4. Skor 0 untuk jawaban "tidak pernah" dan skor 4 untuk jawaban "hampir selalu". Semakin tinggi skor dalam ZCBS maka semakin tinggi persepsi caregiver terhadap beban.

Data yang diperoleh dalam penelitian ini kemudian dianalisis menggunakan program SPSS dengan teknik korelasi product-moment. Tujuannya adalah untuk menjawab hipotesis penelitian tentang adanya hubungan antara beban subjektif dengan kualitas hidup pendamping (caregiver) pasien skizofrenia.

\section{HASIL}

Penelitian ini dilaksanakan di salah satu daerah di kota Yogyakarta yang merupakan salah satu daerah dengan jumlah pasien skizofrenia terbanyak. Pengambilan data dilakukan melalui kerjasama 
dengan Puskesmas setempat yang memiliki wilayah kerja dalam tiga desa dengan jumlah penduduk sebanyak 47.696 jiwa. Data yang diperoleh dari Puskesmas menunjukkan bahwa terjadi peningkatan jumlah pasien skizofrenia dari tahun ke tahun. Artinya, jumlah caregiver pun otomatis akan bertambah.

Penanganan terhadap hal-hal yang berkaitan dengan gangguan kejiwaan, termasuk skizofrenia, memang menjadi salah satu fokus utama poli Psikologi dan poli Jiwa di Puskesmas tersebut. Beberapa kegiatan telah diupayakan, seperti pembentukan kader sehat jiwa, penyuluhan rutin, pendataan, dan pembentukan perkumpulan caregiver. Salah satu faktor yang mendorong terbentuknya perkumpulan caregiver adalah dengan melihat banyaknya keluhan, baik fisik maupun psikologis, yang justru dirasakan oleh caregiver, bukan pasien yang mengalami skizofrenia. Kondisi tersebut berkaitan dengan beban yang dirasakan selama merawat anggota keluarga yang mengalami gangguan kejiwaan. Dampak yang dialami oleh caregiver pun sangat beragam bentuknya, mulai dari munculnya berbagai perasaan tidak nyaman, keluhan fisik, kesulitan finansial, dan terganggunya hubungan dengan lingkungan sosial karena stigma negatif yang masih melekat pada penderita gangguan jiwa.

Penelitian ini sejalan dengan program yang telah dicanangkan oleh pihak Puskesmas mengenai penanganan pada penderita gangguan jiwa maupun caregivernya. Selain itu adanya perkumpulan caregiver juga menjadi salah satu media untuk dapat dilaksanakannya penelitian ini.

Data yang diperoleh dari penelitian ini adalah tingkat kualitas hidup dan beban subjektif yang dirasakan oleh 50 caregiver skizofrenia. Berikut ini adalah data mengenai tingkat kualitas hidup yang diperoleh dari skala WHOQOL-BREF.

Tabel 1. Data Skor Kualitas Hidup

\begin{tabular}{lccc}
\hline \multicolumn{1}{c}{ Kategorisasi } & Skor & Jumlah & Prosentase \\
\hline Sangat Rendah & $0-80$ & 0 & $0 \%$ \\
Rendah & $81-160$ & 13 & $26 \%$ \\
Sedang & $161-240$ & 27 & $54 \%$ \\
Tinggi & $241-320$ & 7 & $14 \%$ \\
Sangat Tinggi & $321-400$ & 3 & $6 \%$ \\
\hline
\end{tabular}

Berdasarkan data di atas dapat dilihat bahwa terdapat $6 \%$ dari subjek yang memiliki kualitas hidup sangat tinggi, $14 \%$ subjek memiliki skor kualitas hidup tinggi, 54\% subjek memiliki skor kualitas hidup sedang, dan $26 \%$ subjek memiliki skor kualitas hidup rendah. Hasil tersebut menunjukkan bahwa sebagian besar caregiver memiliki tingkat kualitas hidup yang termasuk dalam kategori sedang dan $26 \%$ masih tergolong rendah.

Sedangkan untuk skor beban subjektif yang diperoleh dari Zarit Caregiver Burden Scale dapat dilihat pada data di bawah ini.

Tabel 2. Data Skor Beban Subjektif

\begin{tabular}{lccc}
\hline \multicolumn{1}{c}{ Kategorisasi } & Skor & Jumlah & Prosentase \\
\hline Sedikit/Tidak ada beban & $0-21$ & 6 & $12 \%$ \\
Beban ringan - sedang & $21-40$ & 27 & $54 \%$ \\
Beban sedang - berat & $41-60$ & 10 & $20 \%$ \\
Berat & $61-88$ & 7 & $14 \%$ \\
\hline
\end{tabular}


Data di atas menunjukkan bahwa terdapat $12 \%$ caregiver dengan kategori beban sedikit, $54 \%$ merasa memiliki beban ringan sampai sedang, $20 \%$ dengan beban sedang sampai berat, dan $14 \%$ lainnya merasa memiliki beban berat.

Data skor kualitas hidup dan skor beban subjektif subjek dianalisis menggunakan teknik korelasi product-moment. Hasil analisis tersebut menunjukkan bahwa nilai Sig. $=0.00$ dan Sig. $<0.05$. Sedangkan pearson correlation menunjukkan nilai negatif (-). Artinya, terdapat korelasi negatif yang signifikan antara kualitas hidup dengan beban subjektif caregiver skizofrenia. Hal tersebut menunjukkan bahwa semakin tinggi kualitas hidup caregiver skizofrenia maka semakin rendah beban yang dirasakan. Begitu juga sebaliknya, semakin tinggi beban yang dirasakan oleh caregiver maka akan semakin rendah tingkat kualitas hidupnya.

\section{PEMBAHASAN}

Caregiver dapat mengalami tekanan bahkan dalam jangka panjang yang berpengaruh pada kondisi fisik, mental, dan sosial (Darwin dkk, 2013). Hal ini menjelaskan keterkaitannya dengan kualitas hidup, mengingat dimensi kualitas hidup yang menyuluh pada aspek kehidupan manusia, mencakup aspek fisik, psikologis, sosial, dan lingkungan. Fitrikasari (2012) dalam penelitiannya tentang caregiver burden pada caregiver skizofrenia menunjukkan bahwa peran sebagai caregiver memang dapat menimbulkan beban. Tingkat berat atau ringannya beban dapat dipengaruhi oleh perbedaan dalam pengelolaan stres, kemampuan koping, penerimaan serta anggapan terhadap proses perawatan yang sedang berlangsung.

Persepsi memainkan peran penting dalam hal ini. Persepsi positif akan berpengaruh terhadap beban selama menjadi caregiver. Persepsi juga turut berpengaruh saat caregiver harus menghadapi situasi-situasi yang sulit selama proses pendampingan pada anggota keluarga yang mengalami skizofrenia (Prasastyagoya, dkk, 2013). Setiap orang memiliki persepsi yang berbeda-beda atas peran yang sedang dijalankan atau terhadap permasalahan yang sedang dialami. Persepsi yang berbeda-beda pada cagegiver terhadap beban yang dirasakan, atau yang sering disebut dengan beban subjektif, juga akan memberikan dampak yang berbeda-beda.

Goodhead \& McDonald (2007) dalam penelitiannya menunjukkan bahwa menjalankan peran sebagai caregiver juga dapat memberikan dampak positif, disamping dampak negatif yang bisa muncul. Pengaruh positif yang dapat muncul seperti meningkatnya kedekatan dengan anggota keluarga yang menderita skizofrenia karena lebih banyak menghabiskan waktu bersama, meningkatnya rasa tanggung jawab, saling mengasihi dan mendukung satu sama lain. Sejalan dengan yang dikemukakan oleh Savage \& Bailey (2004), menjadi caregiver juga dapat meningkatkan pengembangan pribadi, adanya perasaan lebih dekat dengan pasien, dan dapat meningkatkan harga diri.

Islam juga memandang persepsi sebagai sebuah proses kognitif individu dalam memahami suatu informasi. Proses pemahaman tersebut akan melibatkan panca indra, seperti mata, telinga, hidung, dan hati untuk merasakan. Pemahaman juga melibatkan hati dan akal. Fungsi indera manusia berfungsi sesuai dengan perkembangan fisik. Seseorang akan dapat merasakan berbagai pengaruh eksternal yang melibatkan perasaan-perasaan dan mempengaruhi persepsi dan pengetahuan (Najati, 2001).

Begitu juga dengan persepsi yang dimiliki oleh caregiver terhadap beban yang dimiliki juga dapat berpengaruh pada berbagai aspek dalam kehidupan sehari-hari yang pada akhirnya dapat berpengaruh pada tinggi rendahnya kualitas hidup. Kemampuan seseorang dalam mengatasi peristiwa yang penuh 
dengan tekanan tanpa mengalami distres subjektif dapat menjadi faktor utama agar tidak terjebak pada kondisi yang penuh dengan krisis (Brown dkk, 2003).

Kualitas hidup merupakan pengalaman internal yang dipengaruhi oleh faktor eksternal dan pengalaman subjektif di masa lalu, kondisi mental, tipe kepribadian, serta harapan-harapan pribadi (Schrag dkk, 2000). Seseorang dapat dikatakan memiliki kualitas hidup yang baik jika kondisi fisik, psikis dan sosial dapat berfungsi dengan baik (Acree dkk, 2006). Kondisi psikis yang dimaksud dapat meliputi persepsi pribadi, dalam hal ini adalah persepsi subjek terhadap beban yang dirasakan atau yang sering disebut dengan beban subjektif.

Hasil penelitian ini menunjukkan bahwa terdapat keterkaitan antara kualitas hidup dengan beban subjektif subjek. Subjek yang memiliki persepsi bahwa beban yang dirasakan ringan ternyata memiliki kualitas hidup yang lebih tinggi dari pada subjek yang merasa memiliki beban berat.

\section{KESIMPULAN}

Berdasarkan hasil penelitian yang telah dilaksanakan, dapat disimpulkan bahwa terdapat korelasi negatif yang signifikan antara kualitas hidup dengan beban subjektif caregiver skizofrenia. Artinya, semakin tinggi kualitas hidup caregiver skizofrenia maka semakin rendah beban yang dirasakan. Begitu juga sebaliknya, semakin tinggi beban yang dirasakan oleh caregiver maka akan semakin rendah kualitas hidupnya.

Melihat adanya keterkaitan antara kualitas hidup dengan beban subjektif yang dirasakan oleh caregiver, dibutuhkan suatu penelitian terkait intervensi psikologis yang bertujuan untuk melatih caregiver agar memiliki pemahaman terkait dengan peran yang sedang dijalankan serta keterampilan baru untuk melatih sudut pandang agar lebih positif terhadap beban yang sedang dirasakan. Penelitian tersebut diharapkan dapat membantu caregiver untuk meningkatkan kualitas hidup serta sebagai sarana untuk menumbuhkan persepsi positif.

\section{DAFTAR PUSTAKA}

Acree L. S. (2006). Journal Health And Quality Of Life Outcomes. University of Oklahoma City.

Badriyah, S. (2011). Keefektifan Konseling Keluarga dalam Memperbaiki Skor Emosi pada Caregiver Pasien Skizofrenia. Jurnal Kedokteran Indonesia, 2 (1), 66-72.

Boyer, L., Urizar, A.C., Richieri, R., Lancon, C., Maldonado, J.G., Auquier, P. (2012). Quality of Life among Caregivers of Patients with Schizophrenia: a Cross-Cultural Comparison of Chilean and French families. BMC Family Practice 2012, 13:42.

Darwin, P., Hadisukanto, G., Elvira, S.D. (2013). Beban Perawatan dan Ekspresi Emosi Pramurawat Pasien Skizofrenia Rumah Sakit Jiwa. Jurnal Indo Med Assoc, 63 (2), 46-51. Jakarta: Departeman Psikiatri, Fakultas Kedokteran Universitas Indonesia/Rumah Sakit Cipto Mangunkusumo.

Dorian M., Gracia, J.R., Lopez, S.R., Hernandez, M.B. (2008). Acceptance and Express Emotion in Mexican American Caregiver of Relative with Schizophrenia. Proquest Journal, 47 (2), 215228

Fitrikasari, A., Kadarman, A., Woroasih, S., Sarjana, W. (2012). Gambaran Beban Caregiver Penderita Skizofrenia di Poliklinik Rawat Jalan RSJ Amino Gondohutomo Semarang. Medica Hospitalia. Med Hosp 2012; 1 (2): 118-122. Semarang: Fakultas Kedokteran Universitas Diponegoro. 
Gani, A. (2014). Di Indonesia, Ada 18 Ribu Penderita Gangguan Jiwa Berat Dipasung. http://www.merdeka.com/peristiwa/di-indonesia-ada-18-ribu-penderita-gangguan-jiwaberat-dipasung.html. Diakses 19 April 2016.

Goodhead, A., \& McDonald, J. (2007). Informal caregivers literature review :A report prepared for the National Health Committee. Wellington: Health Services Research Centre.

Greenberg, J.S, Knudsen, K.J, Aschbrenner, K.A. (2006). Prosocial family processes and the quality of life of persons with schizophrenia. Psychiatr Serv 57:1771-7.

Ibrahim, A. S. (2011).Skizofrenia Spliting Personality. Tangerang: Jelajah Nusa

Lylayuvery (2008). Hubungan stigma dan Kualitas Hidup Caregiver Penderita Skizofrenia Rawat Jalan di Rumah Sakit Ernaldi Bahar Palembang. http://mru.fk.ui.ac.id/index.php?uPage=profil.profil_detail\&smod=profil\&sp=public\&idp enelitian=194

Makmuroch. (2014). Keefektifan Pelatihan Keterampilan Regulasi Emosi terhadap Penurunan Tingkat Ekspresi Emosi pada Caregiver Pasien Skizofrenia di Rumah Sakit Jiwa Daerah Surakarta. Wacana Jurnal Psikologi. 6 (11), 13-34. Program Studi Psikologi Fakultas Kedokteran Universitas Sebelas Maret.

Margetic, B.A., Jakovljevic, M., Furjan, Z., Margetic, B., Marsanic, V.B. (2013). Qualiti of life of key caregiver of schizophrenia patients and association with kinship. Cent Eur Public Health; 21 (4): 220-223.

Nainggolan, N.J. \& Hidajat, L.L. (2013). Profil Kepribadian dan Psychological Well-Being Caregiver Skizofrenia. Jurnal Psikologi, 6(1), 21-42. Diakses dari http://www.ejournalunisma.net/ pada 26 November 2013.

Najati. (2005). Psikologi dalam Al-Qur'an, Terapi Qur'ani dalam Penyembuhan Gangguan Kejiwaan, Terj. Zaka al-Farisi. Bandung: CV Pustaka Setia.

Peterson, M.E. (2011). Pathological Gambling: Influence of Quality of Life and Psychological Distress on Abstinence After Cognitive-Behavioral Inpatient Treatment. J Gambl Stud (2009), 25:253262.

Riskades. (2013). Riset Kesehatan Dasar. http://www.depkes.go.id. Diakses pada tanggal 3 Juli 2017.

Rubbyana, U. (2012). Hubungan antara Strategi Koping dengan Kualitas Hidup pada Penderita Skizofrenia Remisi Simptom. Jurnal Psikologi Klinis dan Kesehatan Mental. 1 (02), 59-66. Fakultas Psikologi Universitas Airlangga Surabaya.

Sadock B. J., Sadock V. A. (2007). Kaplan \& Sadock's Synopsis of Psychiatry: Behavioral Sciences/Clinical Psychiatry, 10th Edition. Schizophrenia. Lippincott Williams \& Wilkins. Hal: 468-497.

Savage, S. \& Bailey, S., (2004), The impact of caring on caregivers mental health: A review of the literature'. Australian Health Review 27(1), 103-109.

Schrag A, Selaic C, Jahanshanhi M, Qiunn P.N. (2000). The EQ-56-ageneric quality of measure is useful instrument to measure quality of life in atients with Parkinson's disease. I Neurol Neurosurg Psychiatry. 69: 67-73.

Siswanto. (2007). Kesehatan Mental: Konsep, Cakupan, dan Perkembangan. Yogyakarta: Penerbit Andi 
Stanley, S., Shwetha, S. (2006). Integrated Psychosocial Intervension in Schizophrenia: Implications for Patients and Caregivers: a Study from India. The International Journal of Psychosocial Rehabilitation.10 (2), 113-128.

Swaroop, N., Ravi, S., Goud. B.R., Archana, M., Pius, T.M., Pal, A., John, V., Agrawal, T., Jayaram, G. (2013). Burden among caregivers of mentally-III patients: a rural community-based study. International Journal of Research \& Development of Health. 1 (2), 32.

World Health Organization (2004). The World Health Organization's WHOQOL-BREF Quality of Life Assessment: Psychometric Properties and Results of The International Field Trial a Report from the WHOQOL Group. Quality of Life Research, 13:299-310.

World Health Organization. (1996). WHOQOL-BREF: Introduction, administration, scoring and generic version of the assessment. Geneva: WHO.

World Health Organization. (2004). The World Health Organization Quality of Life (WHOQOL)-BREF. Diterjemahkan oleh Dr Ratna Mardiati; Satya Joewana, Catholic University Atma Jaya, Jakarta; Dr Hartati Kurniadi; Isfandari, Indonesia Ministry of Health and Riza Sarasvita, Fatmawati Drug Dependence Hospital, Jakarta.

Yenny dan Herwana, E. (2006). Prevalensi Penyakit Kronis dan Kualitas Hidup Pada Lanjut Usia di Jakarta Selatan. Jurnal Universa Medicina Fakultas Kedokteran Universitas Trisakti, 25 (4), 164-171. 
Anisa Fitriani dan Agustin Handayani 